\title{
Microstructural Evolution and Mechanical Properties in Superlight Mg-Li Alloy Processed by High-Pressure Torsion
}

\author{
Qian Su ${ }^{1,2}$, Jie Xu ${ }^{1,2, *}$, Yuqiao Li ${ }^{1,2}$, Jae Ik Yoon ${ }^{3}$, Debin Shan ${ }^{1,2}$, Bin Guo ${ }^{1,2}$ and \\ Hyoung Seop Kim ${ }^{3, *}$ \\ 1 Key Laboratory of Micro-Systems and Micro-Structures Manufacturing of Ministry of Education, \\ Harbin Institute of Technology, Harbin 150080, China; 14B909052@hit.edu.cn (Q.S.); \\ liyuqiaohit@126.com (Y.L.); shandebin@hit.edu.cn (D.S.); guobin@hit.edu.cn (B.G.) \\ 2 School of Materials Science and Engineering, Harbin Institute of Technology, Harbin 150001, China \\ 3 Department of Materials Science and Engineering, Pohang University of Science and Technology, \\ Pohang 37673, South Korea; suq33023@gmail.com \\ * Correspondence: xjhit@hit.edu.cn (J.X.); hskim@postech.ac.kr (H.S.K.); Tel.: +86-451-86402775 (J.X.); \\ $+82-54-2792150$ (H.S.K.)
}

Received: 3 March 2018; Accepted: 3 April 2018; Published: 13 April 2018

\begin{abstract}
Microstructural evolution and mechanical properties of LZ91 Mg-Li alloy processed by high-pressure torsion (HPT) at an ambient temperature were researched in this paper. The microstructure analysis demonstrated that significant grain refinement was achieved after HPT processing with an average grain size reducing from $30 \mu \mathrm{m}$ (the as-received condition) to approximately $230 \mathrm{~nm}$ through 10 turns. X-ray diffraction analysis revealed LZ91 alloy was consisted of $\alpha$ phase (hexagonal close-packed structure, hcp) and $\beta$ phase (body-centered cubic structure, bcc) before and after HPT processing. The mean value of microhardness increased with the increasing number of HPT turns. This significantly increased hardness of specimens can be explained by Hall-Petch strengthening. Simultaneously, the distribution of microhardness along the specimens was different from other materials after HPT processing due to the different mechanical properties of two different phases. The mechanical properties of LZ91 alloy processed by HPT were assessed by the micro-tensile testing at $298,373,423$, and $473 \mathrm{~K}$. The results demonstrate that the ultra-fine grain LZ91 Mg-Li alloy exhibits excellent mechanical properties: tensile elongation is approximately $400 \%$ at $473 \mathrm{~K}$ with an initial strain rate of $1 \times 10^{-2} \mathrm{~s}^{-1}$.
\end{abstract}

Keywords: microstructure; mechanical property; ultrafine-grains; high-pressure torsion; $\mathrm{Mg}$-Li alloys

\section{Introduction}

Severe plastic deformation (SPD) is an effective method to produce ultra-fine grained (UFG) materials and it has received significant attention in the last two decades for the superior mechanical and physical properties produced in this way [1,2]. Typically, the grain size of materials processed by SPD is in the sub-micrometer or nanometer area. Some SPD processes are reported in the previous researches, such as the equal-channel angular pressing (ECAP) [3,4], high-pressure torsion (HPT) $[5,6]$, and accumulative roll-bonding (ARB) [7-9]. Among them, HPT processing is particularly attractive due to the fact that processed grains are remarkably smaller than other techniques by experimental results [10-12]. The ultra-fine grain (UFG) materials processed by this method have excellent physical and mechanical properties, such as high intensity, good toughness, excellent ductility, and the potentiality of forming a superplastic at high strain rates [13]. 
Magnesium (Mg) alloys are widely used in the area of aerospace, railway, and automotive industries in view of their low density, high damping property, high cycle capacity, and lower energy demand $[14,15]$. However, the formability of magnesium alloys at ambient temperature is poor because of the limited slip systems of hcp structure [16]. Consequently, poor plasticity and cold formability at ambient temperature restrict their wide application [17,18]. Adding lithium (Li) into $\mathrm{Mg}$ alloys can reduce the axial ratio (c/a) of the hcp lattice and introduce phases with bcc structure which have more slip systems improving the deformation behavior effectively [19]. On the other hand, the strength of $\mathrm{Mg}$ alloys will be reduced due to the addition of $\mathrm{Li}$ element. In fact, $\mathrm{Mg}-\mathrm{Li}$ alloy is the lightest metal structural material with high stiffness, excellent machinability, good magnetic-shielding, and resistance, whereas the strength of $\mathrm{Mg}-\mathrm{Li}$ alloys is very low [20-22]. Usually, previous way to increase strength included addition of $\mathrm{Zn}, \mathrm{Al}$, or rare earth elements (RE); or addition of Sn with subsequent SPD and heat treatment. There is currently wide research activity on SPD processing of $\mathrm{Mg}$ alloys [23] including some research about grain refinement of HPT-processed Mg-Li alloys [24-26]. By describing the evolution of microstructure and micro-hardness after HPT processing, and the influence of HPT processing on the strength and ductility obtained from tensile testing at different temperatures, this paper provides detailed information about the HPT processing on LZ91 Mg-Li alloy and the subsequent mechanical performance when it was tensile tested at different temperatures.

\section{Materials and Methods}

Commercial LZ91 Mg-Li alloy rods with a diameter of $10.0 \mathrm{~mm}$ were used in this paper and the LZ91 alloy composition is shown in Table 1. Figure 1 shows the microstructure of the as-received LZ91 alloy observed by metallographic microscope (OLYMPUS, GX71, Olympus Company, Tokyo, Japan), where the white areas are $\alpha$ phase and the gray areas are $\beta$ phase. The initial average grain size was approximately $30 \mu \mathrm{m}$ from the result of Figure 1a. Meanwhile, both $\alpha$ phase and $\beta$ phase were stretched along the extrusion direction and distributed homogeneously.

Table 1. The LZ91 alloy composition.

\begin{tabular}{ccccc}
\hline Element & Li & Zn & Mn & Else \\
\hline Content (wt \%) & 8.92 & 0.97 & 0.1 & $/$ \\
\hline
\end{tabular}

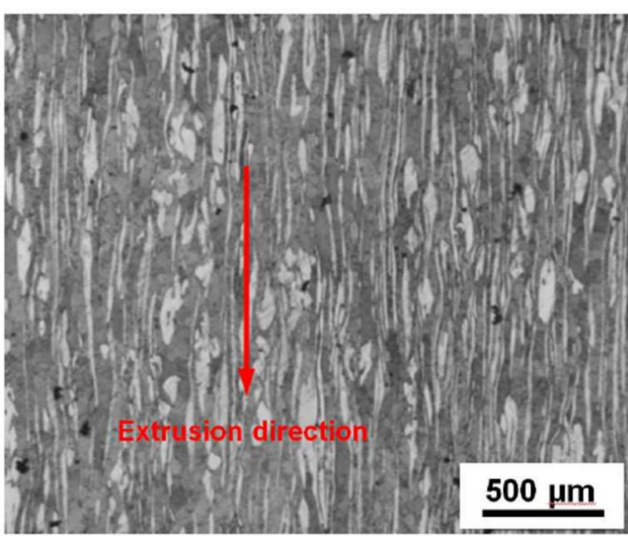

(a)

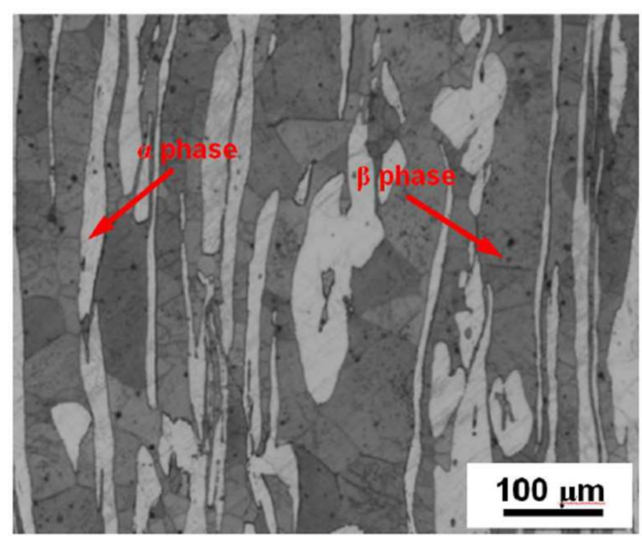

(b)

Figure 1. OM images of the as-received LZ91 alloy at (a) 50× and (b) $200 \times$.

The LZ91 alloy rods were cut into disks with thicknesses of $1.5 \mathrm{~mm}$ first and then these disks were polished on two sides carefully before HPT processing. For processing of HPT, every disk was put in the depression of the lower anvil and then the two anvils of HPT processing machine were brought together with an imposed pressure. In this paper, all disks were processed with an imposed pressure 
(P) of 6.0 GPa at ambient temperature. Torsional straining was achieved by rotating the lower anvil with a rotation speed of $1 \mathrm{rpm}$. In addition, the rotation turns were $\mathrm{r} 1 / 4,1,5$, and 10, respectively. Then these HPT processed disks were ground on SiC papers in series to 1200 , and then the disks were mechanically polished to a mirror-like surface.

X-ray diffraction (XRD) was carried out for the quantitative phase analysis on the LZ91 alloy before and after HPT processing with different numbers of turns. The radiation of XRD experiments was $\mathrm{Cu}$ $\mathrm{K} \alpha$ with a wave length $\lambda=0.15418 \mathrm{~nm}$ and the scanning range were $20^{\circ}$ to $100^{\circ}$. To characterize the microstructure of LZ91 alloy processed by HPT with various numbers of turns, transmission electron microscopy (TEM, Tecnai G2 F30, FEI Company, Hillsboro, OR, USA) was carried out. The thin sections used in the experiment were obtained on a position of $2.5 \mathrm{~mm}$ from the center of the LZ91 alloy samples processed by HPT by ion thinning.

Microhardness test was performed on the polished disks by a Shimadzu micro-hardness tester (Shimadzu, Kyoto, Japan) which was equipped with a Vickers indenter. The indentation load and dwell time of experiment are $100 \mathrm{gf}$ and $10 \mathrm{~s}$, respectively. The hardness of every disk was measured from the center along the radial direction with spacing of $0.5 \mathrm{~mm}$ between two indentations.

The mechanical properties of the LZ91 alloy before and after HPT were determined using micro-tensile testing. The tensile samples were cut from disks using electro-discharge machining with symmetric off-center positions and the sample size was shown in Figure 2. Before the testing, tensile specimens were first ground on SiC papers in series to 1200\# and then electropolished to remove swirl. The micro-tensile testing was performed at ambient temperature and elevated temperatures of 373, 423 , and $473 \mathrm{~K}$ where the samples were heated by high temperature furnace with an initial stain rate of $1.0 \times 10^{-2} \mathrm{~s}^{-1}$.

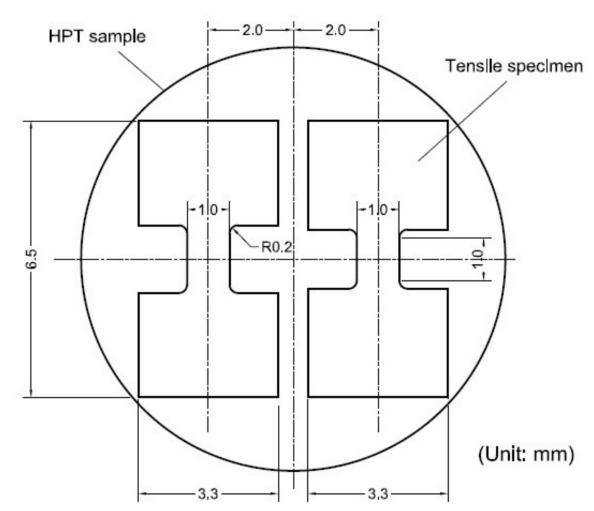

Figure 2. Sample size of micro-tensile testing.

\section{Results}

\subsection{Microstructural Characteristics before and after HPT}

The XRD spectrum presented in Figure 3 shows a quantitative phase analyses of the LZ91 alloy before and after HPT processing with different torsion turns. The results shown in Figure 1 reveal that the LZ91 alloy includes two different phases which are $\alpha$ phase (high content of Mg element) and $\beta$ phase (high content of Li element). Meanwhile, there is no change in the phase composition of LZ91 alloy after HPT processing with different turns.

Figure 4 shows the TEM micrographs of LZ91 alloy after HPT processing with different turns of a $1 / 4, \mathrm{~b} 1, \mathrm{c} 5$, and d 10 at the half-radius position. From the results, it can be seen that the grains of the LZ91 alloy were significantly refined (i.e., decreased from micron-scale to submicron-scale) after HPT processing. To express the evolution of microstructure, grain size evolution during HPT processing was shown in Figure 5. 
In the early period of HPT processing, shear bands with a high dislocation density were formed because of severe plastic deformation. When the dislocation density reached a threshold value, the grain would disintegrate to subgrains, which were separated by small angle grain boundaries. With further processing of HPT, deformation occurred on shear bands which were located at previously unstrained parts of the material. The size of grain decreased steadily, and the shear bands coalesced. Thereafter, the small angle grain boundaries were displaced by large angle grain boundaries [27,28]. From the embedded TEM photograph in Figure 4a, a significant amount of dislocation pile-up, labeled by white elliptical regions, was formed. The average strain of atomic-level increased on account of the increasing of dislocation density. The selected area electron diffraction (SAED) patterns of Figure 4c,d show that the grain boundaries have high angles of misorientation [29,30]. Therefore, the grains of LZ91 alloy were refined significantly from $\sim 30 \mu \mathrm{m}$ to $\sim 950 \mathrm{~nm}$ processed by HPT after $1 / 4$ turn. During the period between $1 / 4$ and 1 turn, the volume ratio of grain boundaries increased due to grain refinement, which resulted in the use of much more energy to continue the refining process. However, the input mechanical energy, part of which transforms into internal energy in the grains, is constant. Therefore, the refining rate declined. After 1 turn, the average grain size could reach about $260 \mathrm{~nm}$. Meanwhile, dynamic balance was achieved between the grain refining caused by plastic deformation and grain growth induced by thermal effect [31]. Even so, the grains of the LZ91 alloy were refined slightly. After 10 turns, the grains were refined to $230 \mathrm{~nm}$, although some nanocrystalline grains formed with size of $\sim 90 \mathrm{~nm}$, as shown in Figure $4 \mathrm{~d}$. This grain refinement is in line with the earlier researches of various magnesium alloys processed by HPT at room temperature [32-40], as documented in Table 2.

Table 2. Grain sizes of magnesium and its alloys processed by HPT.

\begin{tabular}{|c|c|c|c|c|c|}
\hline \multirow{2}{*}{ Material } & \multicolumn{3}{|c|}{ HPT } & \multirow{2}{*}{ Grain Size (nm) } & \multirow{2}{*}{ Reference } \\
\hline & Turns & Pressure(GPa) ' & Temperature & & \\
\hline $\mathrm{Mg}-8 \% \mathrm{Li}$ & 5 & 3.0 & RT & $\sim 500$ & Matsunoshita et al. [32] \\
\hline $\mathrm{Mg}-8 \% \mathrm{Li}$ & 20 & 6.0 & RT & $\sim 240$ & Edalati et al. [33] \\
\hline Pure Mg & 10 & 6.0 & RT & $\sim 1000$ & Figueiredo et al. [34] \\
\hline AZ31 & 5 & 6.0 & RT & 900-1200 & Huang et al. [35] \\
\hline AZ31 & 10 & 6.0 & RT & $\sim 110$ & Xu et al. [30] \\
\hline AZ31 & 15 & 2.5 & $\mathrm{RT}$ & $\sim 150-200$ & Stráská et al. [36] \\
\hline ZK60 & 5 & 2.0 & RT & $\sim 1000$ & Torbati-Sarraf et al. [37] \\
\hline ZK60A & 5 & 6.0 & RT & $\sim 2000-5000$ & Lee et al. [38] \\
\hline AZ80 & 10 & 6.0 & $\mathrm{RT}$ & $\sim 200$ & Alsubaie et al. [39] \\
\hline $\mathrm{Mg}-3.4 \mathrm{Zn}$ & 20 & 5.0 & RT & $\sim 140$ & Meng et al. [40] \\
\hline $\mathrm{Mg}-8.92 \% \mathrm{Li}$ & 10 & 6.0 & RT & $\sim 230$ & Present paper \\
\hline
\end{tabular}

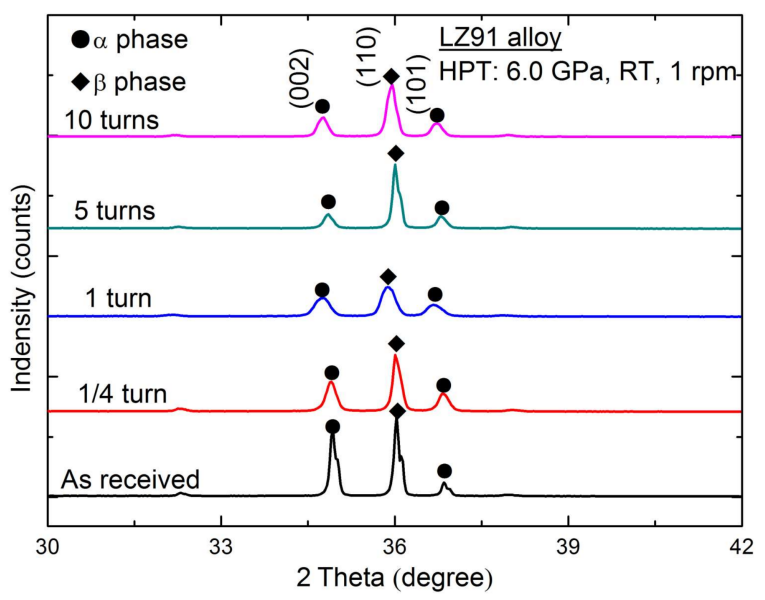

Figure 3. XRD patterns of LZ91 alloys before and after HPT processing. 


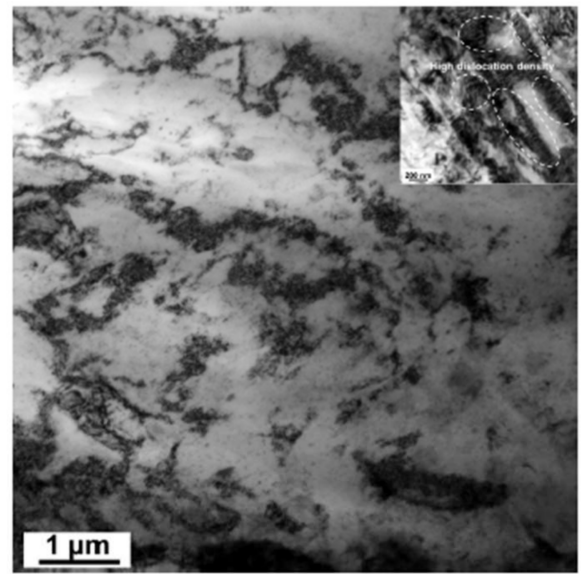

(a)

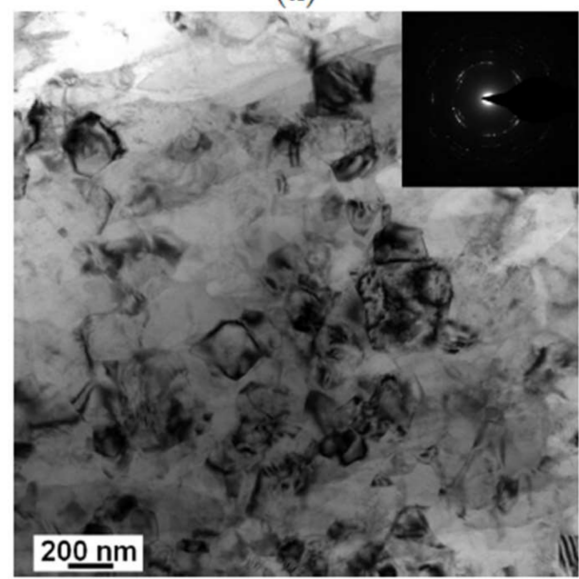

(c)

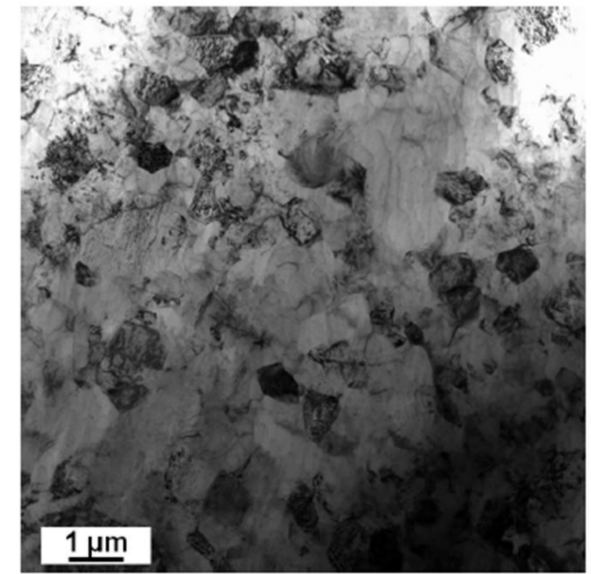

(b)

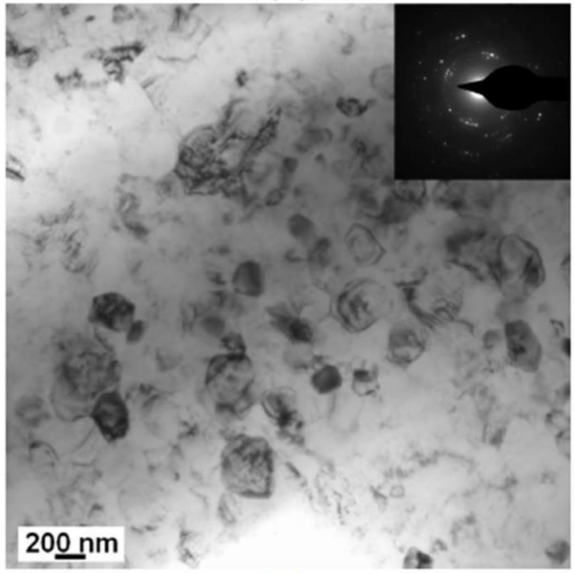

(d)

Figure 4. TEM images of LZ91 alloy after HPT processing with different turns of (a) $1 / 4$; (b) 1 ; (c) 5 ; and (d) 10 at the one-half radius position.

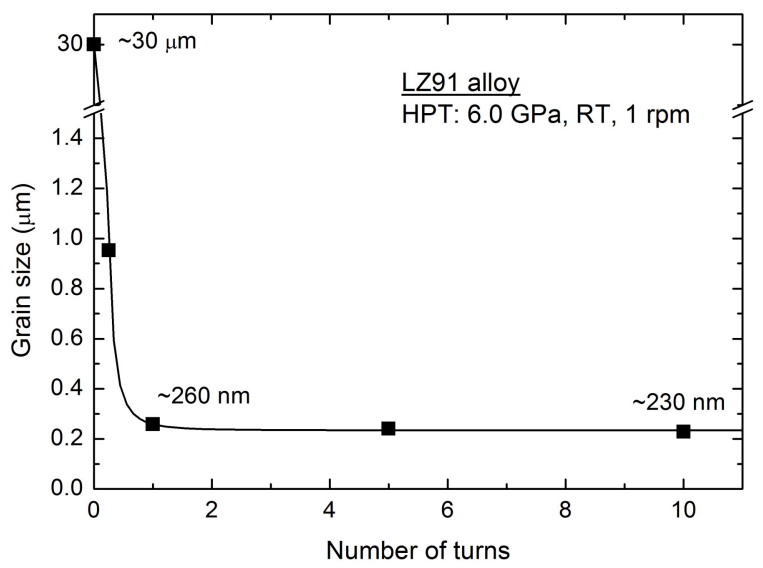

Figure 5. Average grain size of LZ91 alloy before and after HPT processing with increasing torsion turns.

\subsection{Microhardness Evaluation during HPT Processing}

Figure 6a shows the variation of Vickers microhardness along the radial direction of LZ91 alloy before and after HPT processing with 1/4, 1, 5, and 10 turns. Figure $6 \mathrm{~b}$ shows the average values of Vickers microhardness shown in Figure 6a. The lower black line shows the initial microhardness for the 
original LZ91 alloy. These results reveal that the microhardness increased for the LZ91 alloy processed by HPT after $1 / 4$ turn where the hardness increased from $\sim 49 \mathrm{Hv}$ to $\sim 62 \mathrm{Hv}$, and the microhardness of LZ91 alloy processed by HPT became homogeneous after five turns. However, the variation of Vickers hardness along the radius of disk after HPT processing for LZ91 alloy is different from the previous reports. This difference may be caused by the existing of different two phases.

As shown in Figure 4a,b, the microstructure of LZ91 alloy is inhomogeneous after 1/4 and 1 turn, and the two phases have different mechanical properties, so the distribution of microhardness for LZ91 alloy processed by HPT after 1/4 and1 turn is different from earlier reports. After 5 and 10 turns, the microstructure becomes homogeneous as shown in Figure $4 c, d$, and the influence of two different phases decreases, so the distribution of microhardness becomes homogeneous.

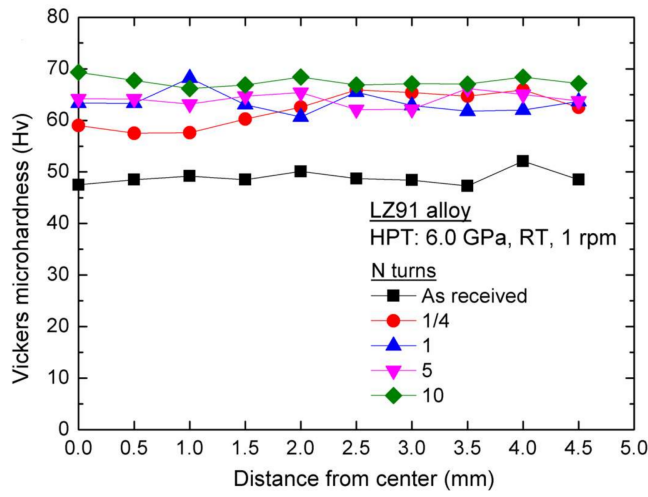

(a)

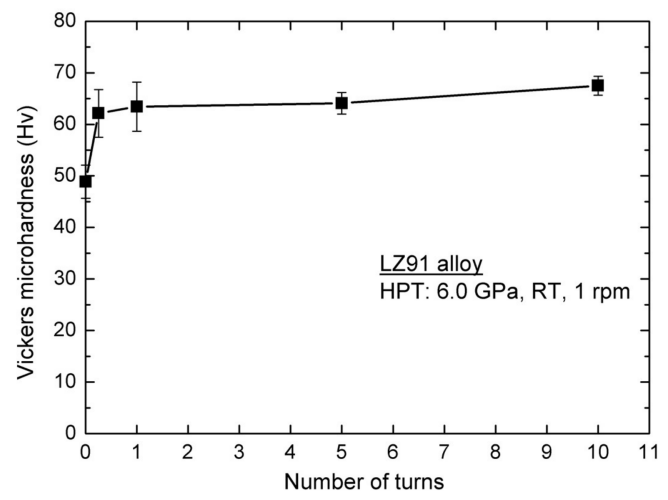

(b)

Figure 6. Vickers microhardness of LZ91 alloy (a) Along the radius of disk and (b) Average values before and after HPT processing with various number of turns.

\subsection{Tensile Behavior before and after HPT Processing}

Mechanical properties of the LZ91 alloy before and after HPT processing were evaluated using micro-tensile tests. Figure 7 shows the engineering stress-engineering strain curves of LZ91 alloy before and after HPT processing through 1/4, 1, 5, and 10 turns at room temperature with an initial strain rate of $1 \times 10^{-2} \mathrm{~s}^{-1}$. The results showed that the yield stress obviously increased with increasing torsion turns of HPT at $298 \mathrm{~K}$.

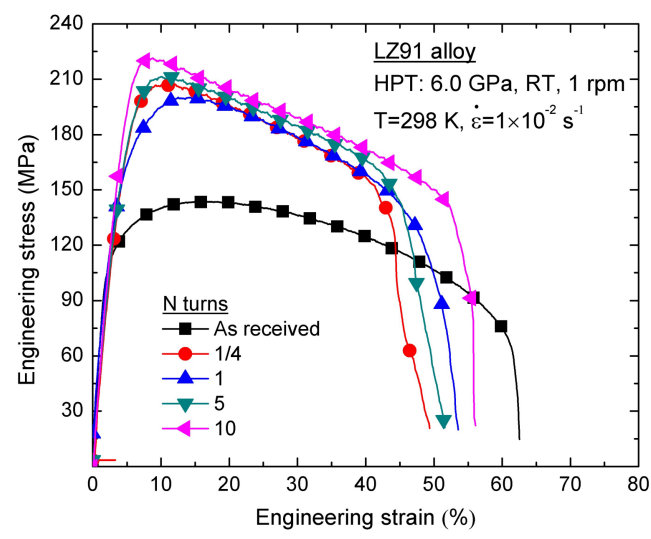

Figure 7. Engineering stress-engineering strain curves of LZ91 alloy before and after HPT processing through $1 / 4,1,5$, and 10 turns at room temperature with an initial strain rate of $1 \times 10^{-2} \mathrm{~s}^{-1}$.

The yield stress of the LZ91 alloy processed by HPT could reach 152 MPa after 10 turns, (1.7 times that of the as-received alloy). This result is mainly attributed to the Hall-Petch effect (i.e., grain size 
strengthening [41,42]), by which the strength increases with decreasing grain size. As analyzed in Section 3.1, the grains of LZ91 alloy were refined significantly from $30 \mu \mathrm{m}$ to about $230 \mathrm{~nm}$. Hence, the volume ratio of the grain boundary increased significantly, which would restrict the movement of dislocations across grain boundaries during plastic deformation at low temperature. Therefore, the yield stress of the specimens improved after HPT processing at low temperature, and this result is in line with the analysis in Section 3.2.

In the plastic deformation processing, dislocation pile-up on grain boundaries is achieved. Therefore, the refined grains would also induce decrease of the ductility. As shown in Figure 7, the elongation to failure decreased after HPT processing. Figure 8 shows the micro-tensile fracture appearance fracture morphology of the LZ91 alloy before and after HPT processing, with different turns at $298 \mathrm{~K}$. Before HPT processing, there were plenty of large, deep dimples, which accounted for the superior ductility of the extruded alloy as shown in Figure 8a. As shown in Figure 8b-e, the number of dimples decreased after HPT, and the dimples become small and shallow. Meanwhile, tearing ridges were observed in the fracture morphology. The evolution of the micro-tensile fracture morphology corresponds with the decrease of ductility.

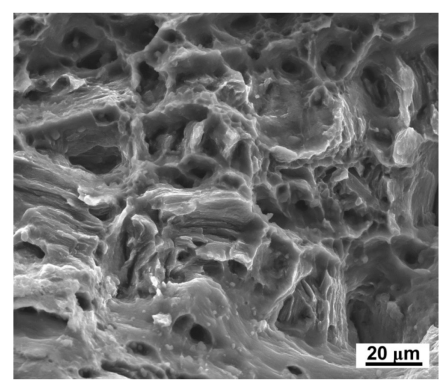

(a)

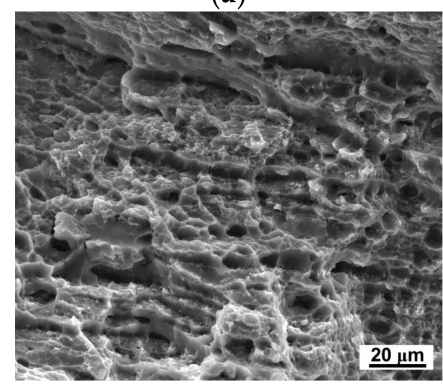

(d)

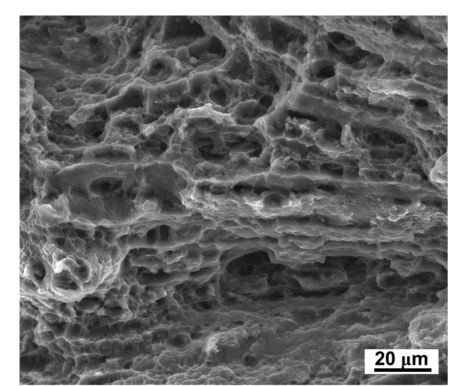

(b)

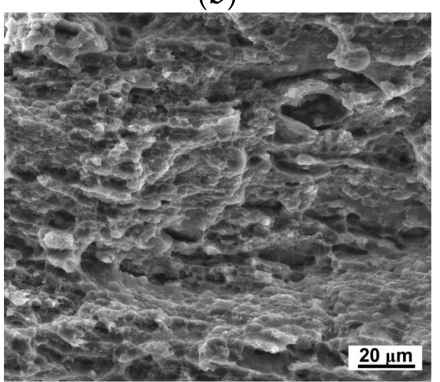

(e)

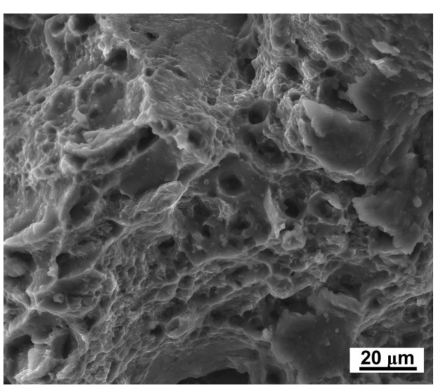

(c)

Figure 8. Micro-tensile fracture morphology of the LZ91 alloy (a) Before and after HPT processing through (b) $1 / 4$; (c) 1 ; (d) 5 , and (e) 10 turns.

Figure 9 shows the engineering stress-engineering strain curves of LZ91 alloy before and after HPT processing through 10 turns at different temperatures with an initial strain rate of $1 \times 10^{-2} \mathrm{~s}^{-1}$. The results indicate that the yield strength decreases and elongation increases with increasing temperature of deformation. Meanwhile, the samples before and after HPT all exhibited high ductility at high temperature, and the plasticity after HPT processing was better than the original material. The measured elongation to failure of the LZ91 alloys before and after HPT processing with 10 turns from $298 \mathrm{~K}$ to $473 \mathrm{~K}$ using a strain rate of $1 \times 10^{-2} \mathrm{~s}^{-1}$ is presented in Figure 9 . As analyzed by the previous micro-tensile results at room temperature, there was a slight decrease of ductility after HPT processing. However, at elevated temperature the ductility improved, and the increase of ductility after HPT processing was more significant with increasing temperature. At a temperature of $473 \mathrm{~K}$, the measured elongations to failure of LZ91 alloy after HPT processing with 10 turns could reach approximately $400 \%$ at an initial strain rate of $1 \times 10^{-2} \mathrm{~s}^{-1}$. 
The improvement of ductility at elevated temperature could mainly be attributed to the grain refinement. At elevated temperature, both the grain interior strength and grain boundary strength decreased; however, the grain boundary strength was more sensitive to temperature. At elevated temperature, the rotation and sliding of grains were easier in fine-grained materials. Therefore, the LZ91 alloy processing by HPT after 10 turns with an average grain size of $\sim 230 \mathrm{~nm}$ presents excellent high-temperature ductility. Figures 10 and 11 show the micro-tensile fracture morphology of LZ91 alloy before and after HPT processing through 10 turns at different temperatures. From these results, we can see that the number of dimples increased with increasing temperature, and the dimples became deeper and bigger. The evolution of the micro-tensile fracture morphology corresponds to the increase of ductility.

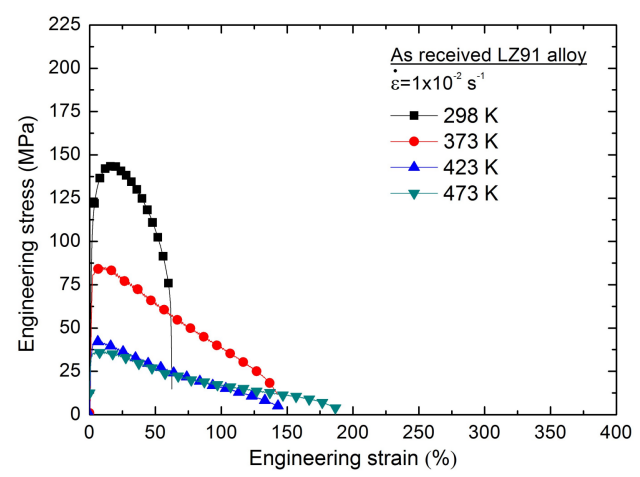

(a)

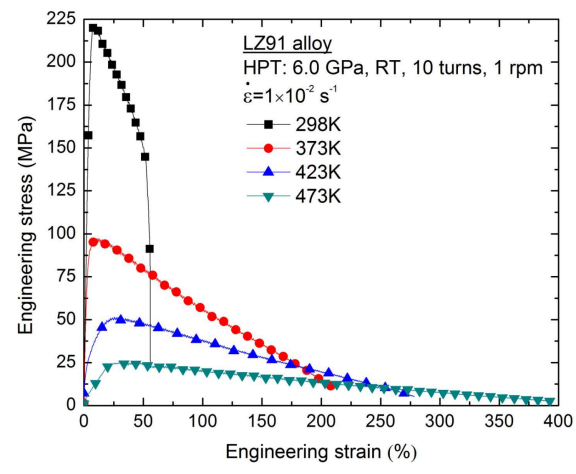

(b)

Figure 9. Engineering stress-engineering strain curves of LZ91 alloy (a) Before and (b) After HPT processing through 10 turns at different temperatures with a strain rate of $1 \times 10^{-2} \mathrm{~s}^{-1}$.

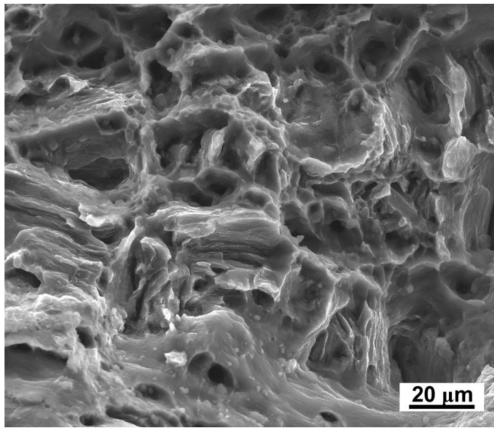

(a)

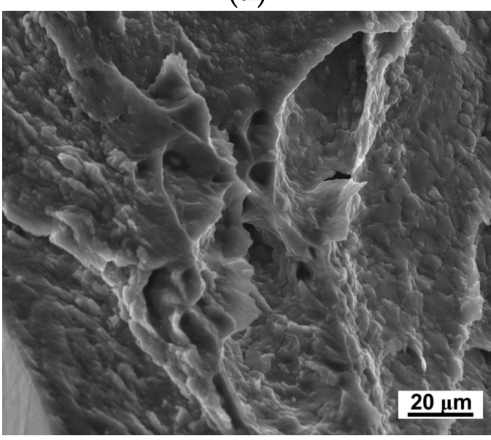

(c)

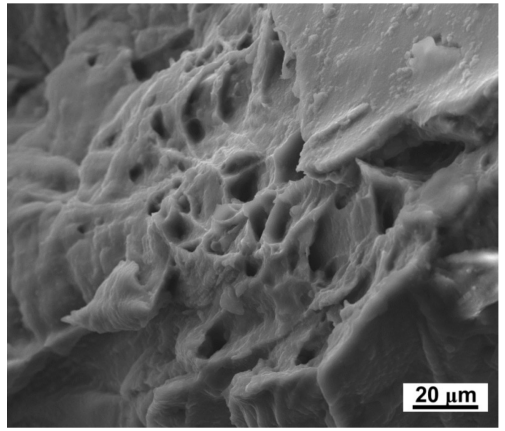

(b)

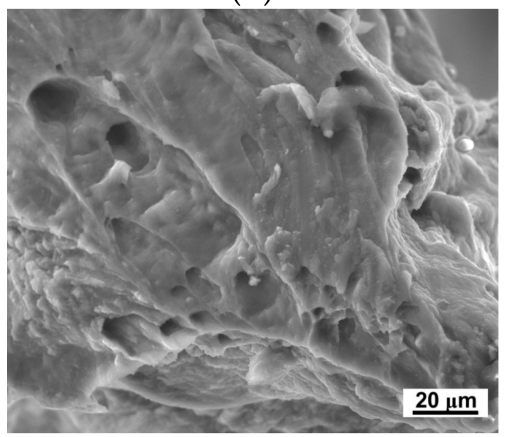

(d)

Figure 10. Micro-tensile fracture morphology of the original LZ91 alloy at temperature of (a) $298 \mathrm{~K}$; (b) $373 \mathrm{~K}$; (c) $423 \mathrm{~K}$; and (d) $473 \mathrm{~K}$. 


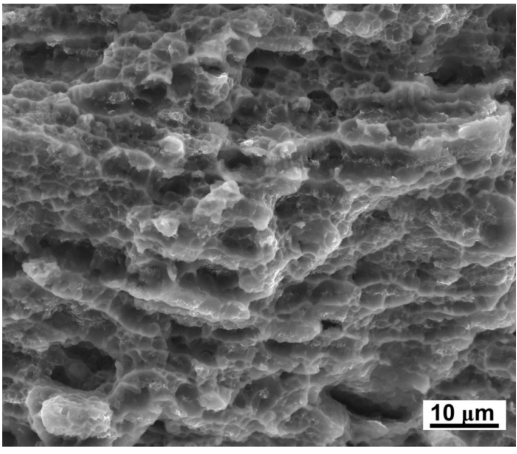

(a)

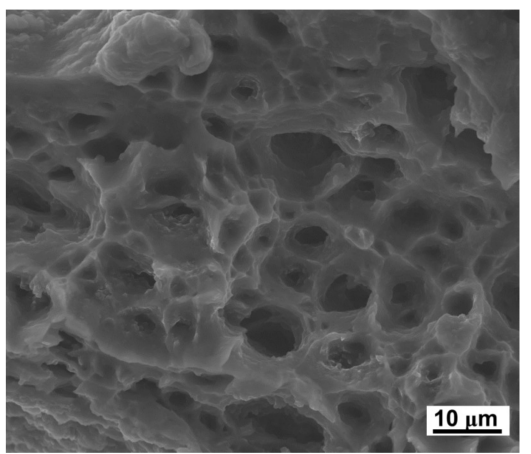

(c)

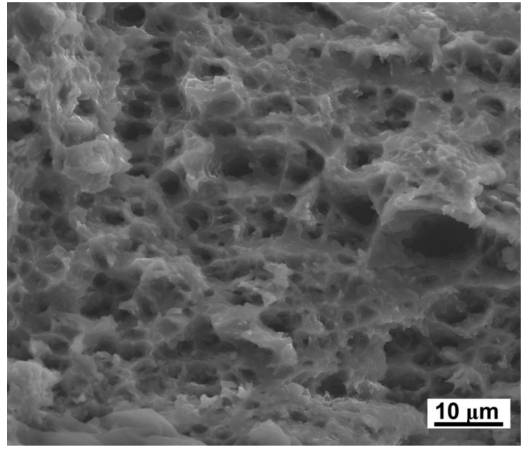

(b)

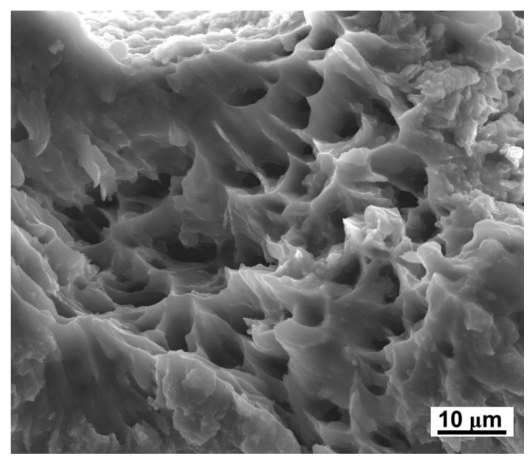

(d)

Figure 11. Micro-tensile fracture morphology of the LZ91 alloy processed by HPT through 10 turns at temperatures of (a) $298 \mathrm{~K}$; (b) $373 \mathrm{~K}$; (c) $423 \mathrm{~K}$; and (d) $473 \mathrm{~K}$.

\section{Discussion}

\subsection{Microstructural Evolution in the Mg-Li Alloy after Processing by HPT}

The microstructural evolution of Mg-Li alloy during HPT processing indicates the possibility of preparing UFG LZ91 alloy with homogenous microstructure through HPT processing. From previous results, it can be seen that the average grain size of the LZ91 alloy was reduced significantly from $\sim 30 \mu \mathrm{m}$ to $\sim 260 \mathrm{~nm}$ after $1 \mathrm{turn}$. However, after $1 \mathrm{turn}$, the refining rate declined due to part of input mechanical energy transforms into internal energy in the grains. After HPT processing through 5 turns, the microstructure of LZ91 alloy, with an average size of $240 \mathrm{~nm}$, becomes homogeneity. In addition, the average grain size was reduced to $230 \mathrm{~nm}$ after 10 turns finally. In general, with the increasing torsion turns of HPT, the grain size decreases where the grain size changes from $\sim 30 \mu \mathrm{m}$ to $\sim 230 \mathrm{~nm}$ after HPT processing through 10 turns at room temperature Therefore, it is confirmed that HPT processing is an effective and superior method to obtain an UFG Mg-Li alloy with singularly fine grains and homogeneous microstructure.

\subsection{Microhardness Evolution in the Mg-Li Alloy after Processing by HPT}

During HPT processing, the grain refining was achieved due to severe plastic deformation. The average grain size of LZ91 alloy decreased from $\sim 30 \mu \mathrm{m}$ (as received) to $\sim 230 \mathrm{~nm}$ (after HPT processing through 10 turns). The improved microstructure with fine grain can contribute the increasing and homogeneity of hardness. After HPT processing through 10 turns, the average hardness across the disk is approximately $68 \mathrm{Hv}$ as presented by Figure 6 . 
In practice, the relationship between the microhardness and the equivalent von Mises strain, $\varepsilon_{e q}$, is given from the following expression [43-45]:

$$
\varepsilon_{e q}=\frac{2 \pi N r}{h \sqrt{3}}
$$

where $r$ is the radial range from the center of the specimen and $h$ is the thickness of the specimen. Early experiments show that the microhardness value may be directly related to equivalent strain on HPT processing [46]. This correlation of this paper is shown in Figure 12 where all of the datum points are from Figure 7.

The severe grain refinement during HPT processing induces clear improvement in the hardness due to grain boundary strengthening. Additionally, with the increasing number of HPT turns, the hardness of HPT processed specimens improved. In addition, the regular increasing of hardness may be attribute to Hall-Petch strengthening when the relationship between hardness and grain size is reformulated as follows [47],

$$
H=H_{0}+k_{H} d^{-1 / 2}
$$

where $H$ is the hardness of specimen, $H_{0}$ and $k_{H}$ are the appropriate material constants associated with the hardness measurements.

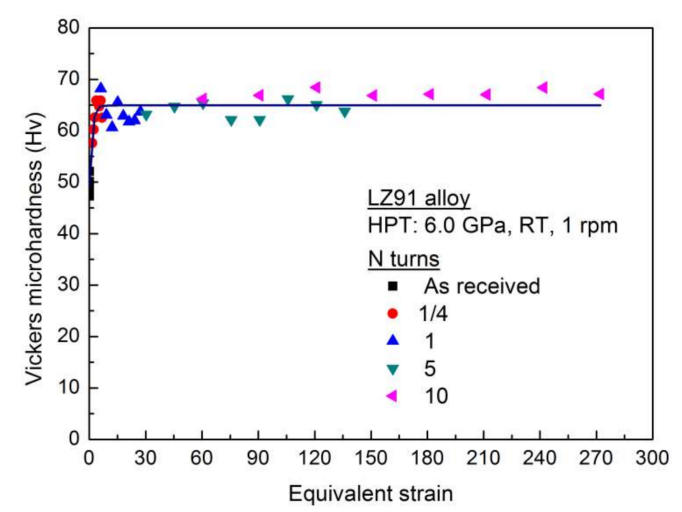

Figure 12. Relationship between Vickers microhardness and equivalent strain for LZ91 alloy before and after HPT processing with various numbers of torsion turns.

The availability of using the Hall-Petch relationship to explain experimental results was demonstrated in earlier researches for other alloys after ECAP or HPT processing [47-50]. For the LZ91 alloy used in this paper, there is no precipitate-hardening and previous researches [26,47] indicate that the solution-hardening has little influence on the strengthening, so Hall-Petch relationship can be used to explain the experimental results in this paper. The Vickers microhardness results shown in Figure 6 were re-plotted as a function of $d^{-1 / 2}$ for LZ91 alloy before and after HPT of 1/4, 1, 5, and 10 turns at the one-half radius position. The result is shown in Figure 13 and the result reveals that there has a conventional linearity relationship between hardness and $d^{-1 / 2}$ for the present LZ91 alloy before and after HPT processing. As shown in the above investigations, the LZ91 alloy exhibited good Hall-Petch strengthening for grain refinement. Simultaneously, the microhardness of the HPT-processed specimens was homogeneous after five or more turns, which is in line with some earlier researches about the gradual improvement of hardness homogeneity for different materials processed by HPT [51-53]. Cumulative deformation of the materials processed by increased with the number of turns, and the material microstructure became uniform when the cumulative deformation increased to saturation values. For these reasons, the microhardness of LZ91 alloy processed by HPT becomes homogeneous after five or more turns. 


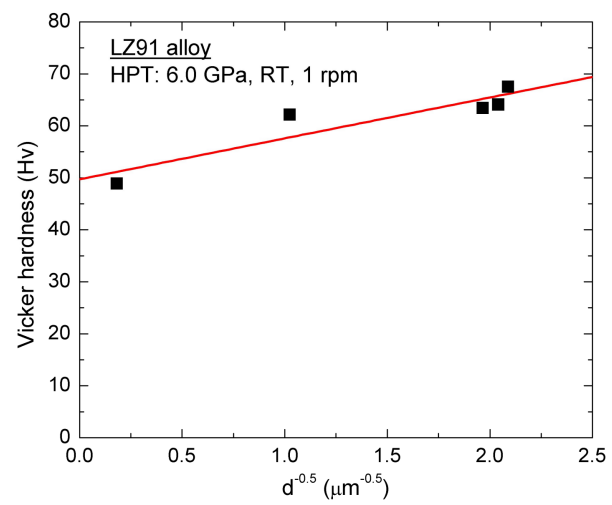

Figure 13. Relationship between Vickers microhardness and $d^{-1 / 2}$ for the LZ91 alloy before and after HPT through 1/4, 15 and 10 turns at the one-half radius position.

\subsection{The Potential Application of the UFG Mg-Li Alloy on Micro-Forming Technology}

In related to micro-forming, the processing is converted from traditionally macroscopic level to micro level. Thus, the effect of grain size on the flow behavior and the overall formability becomes much more significant due to the inherent size effects [54,55]. Particularly, the uneven material performance would be brought about due to grain size effect, which can produce the deviation of the forming shape and lead to inhomogeneous properties of the products. A primary purpose of this study was to evaluate the potential applications of using the alloy in micro-forming for the UFG $\mathrm{Mg}$-Li alloy using micro-tensile testing. As shown by Figures 7 and 9, it was confirmed that during high temperature micro-tensile testing the flow stress decreased and the ductility was improved with increasing numbers of HPT turns. After 10 turns HPT processing, the ductility is improved significantly. The elongation to failure can reach about $400 \%$ at $473 \mathrm{~K}$ with an initial strain rate of $1.0 \times 10^{-2} \mathrm{~s}^{-1}$ which is much higher than the value of as received LZ91 alloy.

These above results reveal that the UFG LZ91 alloy processing by HPT exhibits excellent formability at a relatively low temperature. Therefore, the UFG LZ91 alloy can be used in micro-forming processing with better formality compared with CG materials. Hence, there is potential application of the UFG LZ91 alloy on micro-forming based on present results.

\section{Conclusions}

(1) The Mg-Li alloys were prepared via HPT processing with a pressure of $6.0 \mathrm{GPa}$ up to 10 turns at ambient temperature. The average grain size diminished from $\sim 30 \mu \mathrm{m}$ (the original specimen) to $\sim 230 \mathrm{~nm}$ (the HPT-processed specimen after 10 turns). The XRD results reveal the alloy was consist of hcp $\alpha$-phase and bcc $\beta$-phase before and after HPT processing.

(2) Vickers microhardness measurements indicate the average microhardness increases significantly with increasing number of HPT turns. Meanwhile, after five or more turns, the microhardness of HPT-processed LZ91 alloy is homogeneous. This significantly increased hardness can be explained by Hall-Petch strengthening. The variation of Vickers hardness along the radius of disk after HPT processing for LZ91 alloy is different from the previous reports which can be explained by the existing of two different phases.

(3) The results from micro-tensile testing of the LZ91 alloy before and after HPT indicate that both the strength and ductility of LZ91 are improved with increasing number of HPT turns at both ambient and elevated temperatures. The maximum recorded tensile elongation is approximately $400 \%$ at $473 \mathrm{~K}$ with the initial strain rate of $1 \times 10^{-2} \mathrm{~s}^{-1}$, indicating that after 10 turns HPT processing the ductility is improved significantly.

(4) Based on the experimental results, it is confirmed that the UFG LZ91 Mg-Li alloy processed by HPT processing after 10 turns presents enormous potential application to micro-forming. 
Acknowledgments: This work was supported by the National Natural Science Foundation of China under Grant No. 51475124 and Postdoctoral Scientific Research Development Fund of Heilongjiang Province under Grant No. LBH-Q15039. This work was partially supported by the National Research Foundation of Korea (NRF) grant funded by the Korea government (MSIP) (No. 2014R1A2A1A10051322).

Author Contributions: Qian $\mathrm{Su}$, Jie $\mathrm{Xu}$, and Yuqiao Li conceived and designed the experiments. Jie $\mathrm{Xu}$, Jae Ik Yoon, Debin Shan, Bin Guo and Hyoung Seop Kim supervised the whole project and gave advices on manuscript editing. Qian Su and Yuqiao Li performed the experiments and analyzed the data. Qian Su wrote the paper.

Conflicts of Interest: The authors declare no conflict of interest.

\section{References}

1. Valiev, R.Z.; Islamgaliev, R.K.; Alexandrov, I.V. Bulk nanostructured materials from severe plastic deformation. Prog. Mater. Sci. 2000, 45, 103-189. [CrossRef]

2. Langdon, T.G. Twenty-five years of ultrafine-grained materials: Achieving exceptional properties through grain refinement. Acta Mater. 2013, 61, 7035-7059. [CrossRef]

3. Qiao, X.G.; Ying, T.; Zheng, M.Y.; Wei, E.D.; Wu, K.; Hu, X.S.; Gan, W.M.; Brokmeier, H.G.; Golovin, I.S. Microstructure evolution and mechanical properties of nano-SiCp/AZ91 composite processed by extrusion and equal channel angular pressing (ECAP). Mater. Charact. 2016, 121, 222-230. [CrossRef]

4. Krajnak, T.; Minarik, P.; Gubicza, J.; Mathis, K.; Kuzel, R.; Janecek, M. Influence of equal channel angular pressing routes on texture, microstructure and mechanical properties of extruded AX41 magnesium alloy. Mater. Charact. 2017, 123, 282-293. [CrossRef]

5. Alhajeri, S.N.; Al-Fadhalah, K.J.; Almazrouee, A.I.; Langdon, T.G. Microstructure and microhardness of an Al-6061 metal matrix composite processed by high-pressure torsion. Mater. Charact. 2016, 118, 270-278. [CrossRef]

6. Eskandarzade, M.; Masoumi, A.; Faraji, G.; Mohammadpour, M.; Yan, X.S. A new designed incremental high pressure torsion process for producing long nanostructured rod samples. J. Alloy. Compd. 2017, 695, 1539-1546. [CrossRef]

7. Karimi, M.; Toroghinejad, M.R.; Dutldewicz, J. Nanostructure formation during accumulative roll bonding of commercial purity titanium. Mater. Charact. 2016, 122, 98-103. [CrossRef]

8. Cruz-Gandarilla, F.; Maria Salcedo-Garrido, A.; Bolmaro, R.E.; Baudin, T.; De Vincentis, N.S.; Avalos, M.; Cabanas-Moreno, J.G.; Mendoza-Leon, H. Microstructural evolution and mechanical properties on an ARB processed IF steel studied by X-ray diffraction and EBSD. Mater. Charact. 2016, 118, 332-339. [CrossRef]

9. Mahdavian, M.M.; Khatami-Hamedani, H.; Abedi, H.R. Macrostructure evolution and mechanical properties of accumulative roll bonded Al/Cu/Sn multilayer composite. J. Alloy. Compd. 2017, 703, 605-613. [CrossRef]

10. Zhilyaev, A.P.; Kim, B.K.; Nurislamova, G.V.; Baro, M.D.; Szpunar, J.A.; Langdon, T.G. Orientation imaging microscopy of ultrafine-grained nickel. Scripta Mater. 2002, 46, 575-580. [CrossRef]

11. Zhilyaev, A.P.; Nurislamova, G.V.; Kim, B.K.; Baro, M.D.; Szpunar, J.A.; Langdon, T.G. Experimental parameters influencing grain refinement and microstructural evolution during high-pressure torsion. Acta Mater. 2003, 51, 753-765. [CrossRef]

12. Zhilyaev, A.P.; Kim, B.K.; Szpunar, J.A.; Baro, M.D.; Langdon, T.G. The microstructural characteristics of ultratine-grained nickel. Mat. Sci. Eng. A Struct. 2005, 391, 377-389. [CrossRef]

13. Patil, D.C.; Kori, S.A.; Venkateswarlu, K.; Das, G.; Alhajeri, S.N.; Langdon, T.G. Using ball indentation to determine the mechanical properties of an Al-7475 alloy processed by high-pressure torsion. J. Mater. Sci. 2013, 48, 4773-4779. [CrossRef]

14. Witte, F. The history of biodegradable magnesium implants: A review. Acta Biomater. 2010, 6, 1680-1692. [CrossRef] [PubMed]

15. Polmear, I.J. Magnesium alloys and applications. Mater. Sci. Tech. Lond. 1994, 10, 1-16. [CrossRef]

16. Xu, J.; Shirooyeh, M.; Wongsa-Ngam, J.; Shan, D.; Guo, B.; Langdon, T.G. Hardness homogeneity and micro-tensile behavior in a magnesium AZ31 alloy processed by equal-channel angular pressing. Mat. Sci. Eng. A Struct. 2013, 586, 108-114. [CrossRef]

17. Wang, L.; Qiao, Q.; Liu, Y.; Song, X. Formability of AZ31 Mg alloy sheets within medium temperatures. J. Magnesium Alloy 2013, 1, 312-317. [CrossRef] 
18. Chang, H.W.; Qiu, D.; Taylor, J.A.; Easton, M.A.; Zhang, M.X. The role of Al2Y in grain refinement in Mg-Al-Y alloy system. J. Magnes. Alloy 2013, 1, 115-121. [CrossRef]

19. Yang, Y.; Peng, X.; Wen, H.; Zheng, B.; Zhou, Y.; Xie, W.; Lavernia, E.J. Influence of Extrusion on the Microstructure and Mechanical Behavior of Mg-9Li-3Al-xSr Alloys. Metall. Mater. Trans. A 2013, 44A, 1101-1113. [CrossRef]

20. Chang, T.; Wang, J.; Chu, C.; Lee, S. Mechanical properties and microstructures of various Mg-Li alloys. Mater. Lett. 2006, 60, 3272-3276. [CrossRef]

21. Liu, T.; Wang, Y.D.; Wu, S.D.; Peng, R.L.; Huang, C.X.; Jiang, C.B.; Li, S.X. Textures and mechanical behavior of Mg-3.3\%Li alloy after ECAP. Scripta Mater. 2004, 51, 1057-1061. [CrossRef]

22. Chen, Z.; Dong, Z.; Yu, C.; Tong, R. Microstructure and properties of Mg-5.21Li-3.44Zn-0.32Y-0.01Zr alloy. Mat. Sci. Eng. A Struct. 2013, 559, 651-654. [CrossRef]

23. Figueiredo, R.B.; Aguilar, M.; Cetlin, P.R.; Langdon, T.G. Processing magnesium alloys by severe plastic deformation. IOP Conf. Ser. Mater. Sci. Eng. 2014, 63, 12171. [CrossRef]

24. Ranachowski, Z.; Ranachowski, P.; Rejmund, F.; Pawelek, A.; Piatkowski, A.; Jasienski, Z. The study of influence of high pressure torsion process on acoustic emission activity of compressed Mg-Li alloys. Arch. Acoust. 2008, 33, 123-128.

25. Kudela, S.; Pawelek, A.; Ranachowski, Z.; Piatkowski, A.; Kudela, S., Jr.; Ranachowski, P. Effect of Al alloying on the Hall-Petch strengthening and AE in compressed Mg-Li-Al alloys before and after HPT processing. Kovove Mater. 2011, 49, 271-277. [CrossRef]

26. Srinivasarao, B.; Zhilyaev, A.P.; Gutierrez-Urrutia, I.; Perez-Prado, M.T. Stabilization of metastable phases in Mg-Li alloys by high-pressure torsion. Scripta Mater. 2013, 68, 583-586. [CrossRef]

27. Ivanisenko, Y.; Lojkowski, W.; Valiev, R.Z.; Fecht, H.J. The mechanism of formation of nanostructure and dissolution of cementite in a pearlitic steel during high pressure torsion. Acta Mater. 2003, 51, 5555-5570. [CrossRef]

28. Kratochvil, J.; Kruzik, M.; Sedlacek, R. A model of ultrafine microstructure evolution in materials deformed by high-pressure torsion. Acta Mater. 2009, 57, 739-748. [CrossRef]

29. Suryanarayana, C. Mechanical alloying and milling. Prog. Mater. Sci. 2001, 46, 1-184. [CrossRef]

30. Xu, J.; Wang, X.; Shirooyeh, M.; Xing, G.; Shan, D.; Guo, B.; Langdon, T.G. Microhardness, microstructure and tensile behavior of an AZ31 magnesium alloy processed by high-pressure torsion. J. Mater. Sci. 2015, 50, 7424-7436. [CrossRef]

31. Yu, H.; Sun, Y.; Hu, L.; Zhou, H.; Wan, Z. Microstructural evolution of AZ61-10 at. \% Ti composite powders during mechanical milling. Mater. Design 2016, 104, 265-275. [CrossRef]

32. Matsunoshita, H.; Edalati, K.; Furui, M.; Horita, Z. Ultrafine-grained magnesium-lithium alloy processed by high-pressure torsion: Low-temperature superplasticity and potential for hydroforming. Mat. Sci. Eng. A Struct. 2015, 640, 443-448. [CrossRef]

33. Edalati, K.; Masuda, T.; Arita, M.; Furui, M.; Sauvage, X.; Horita, Z.; Valiev, R.Z. Room-temperature superplasticity in an ultrafine-grained magnesium alloy. Sci. Rep. 2017, 7, 2662. [CrossRef] [PubMed]

34. Figueiredo, R.B.; Poggiali, F.S.J.; Silva, C.L.P.; Cetlin, P.R.; Langdon, T.G. The influence of grain size and strain rate on the mechanical behavior of pure magnesium. J. Mater. Sci. 2016, 51, 3013-3024. [CrossRef]

35. Huang, Y.; Figueiredo, R.B.; Baudin, T.; Brisset, F.; Langdon, T.G. Evolution of Strength and Homogeneity in a Magnesium AZ31 Alloy Processed by High-Pressure Torsion at Different Temperatures. Adv. Eng. Mater. 2012, 14, 1018-1026. [CrossRef]

36. Straska, J.; Janecek, M.; Gubicza, J.; Krajnak, T.; Yoon, E.Y.; Kim, H.S. Evolution of microstructure and hardness in AZ31 alloy processed by high pressure torsion. Mat. Sci. Eng. A Struct. 2015, 625, 98-106. [CrossRef]

37. Torbati-Sarraf, S.A.; Langdon, T.G. Properties of a ZK60 magnesium alloy processed by high-pressure torsion. J. Alloy. Compd. 2014, 613, 357-363. [CrossRef]

38. Lee, H.; Ahn, B.; Kawasaki, M.; Langdon, T.G. Evolution in hardness and microstructure of ZK60A magnesium alloy processed by high-pressure torsion. J. Mater. Res. Technol. 2015, 4, 18-25. [CrossRef]

39. Alsubaie, S.A.; Bazarnik, P.; Lewandowska, M.; Huang, Y.; Langdon, T.G. Evolution of microstructure and hardness in an AZ80 magnesium alloy processed by high-pressure torsion. J. Mater. Res. Technol. 2016, 5, 152-158. [CrossRef] 
40. Meng, F.; Rosalie, J.M.; Singh, A.; Somekawa, H.; Tsuchiya, K. Ultrafine grain formation in Mg-Zn alloy by in situ precipitation during high-pressure torsion. Scripta Mater. 2014, 78-79, 57-60. [CrossRef]

41. Hall, E.O. The Deformation and Ageing of Mild Steel: III Discussion of Results. Proc. Phys. Soc. Sect. B 1951, 64, 747-753. [CrossRef]

42. Petch, N.J. The cleavage strength of polycrystals. J. Iron Steel Inst. 1953, 174, 25-27. [CrossRef]

43. Valiev, R.Z.; Ivanisenko, Y.V.; Rauch, E.F.; Baudelet, B. Structure and deformation behaviour of armco iron subjected to severe plastic deformation. Acta Mater. 1996, 44, 4705-4712. [CrossRef]

44. Wetscher, F.; Vorhauer, A.; Stock, R.; Pippan, R. Structural refinement of low alloyed steels during severe plastic deformation. Mat. Sci. Eng. A Struct. 2004, 387, 809-816. [CrossRef]

45. Wetscher, F.; Pippan, R.; Sturm, S.; Kauffmann, F.; Scheu, C.; Dehm, G. TEM investigations of the structural evolution in a pearlitic steel deformed by high-pressure torsion. Metall. Mater. Trans. A 2006, 37A, 1963-1968. [CrossRef]

46. Vorhauer, A.; Pippan, R. On the homogeneity of deformation by high pressure torsion. Scripta Mater. 2004, 51, 921-925. [CrossRef]

47. Lee, H.; Han, J.; Janakiraman, S.; Ahn, B.; Kawasaki, M.; Langdon, T.G. Significance of grain refinement on microstructure and mechanical properties of an $\mathrm{Al}-3 \% \mathrm{Mg}$ alloy processed by high-pressure torsion. J. Alloy. Compd. 2016, 686, 998-1007. [CrossRef]

48. Furukawa, M.; Horita, Z.; Nemoto, M.; Valiev, R.Z.; Langdon, T.G. Microhardness measurements and the Hall-Petch relationship in an Al-Mg alloy with submicrometer grain size. Acta Mater. 1996, 44, 4619-4629. [CrossRef]

49. Furukawa, M.; Horita, Z.; Nemoto, M.; Valiev, R.Z.; Langdon, T.G. Factors influencing the flow and hardness of materials with ultrafine grain sizes. Philos. Mag. A 1998, 78, 203-215. [CrossRef]

50. Bazarnik, P.; Huang, Y.; Lewandowska, M.; Langdon, T.G. Structural impact on the Hall-Petch relationship in an Al-5Mg alloy processed by high-pressure torsion. Mat. Sci. Eng. A Struct. 2015, 626, 9-15. [CrossRef]

51. Loucif, A.; Figueiredo, R.B.; Baudin, T.; Brisset, F.; Langdon, T.G. Microstructural evolution in an Al-6061 alloy processed by high-pressure torsion. Mat. Sci. Eng. A Struct. 2010, 527, 4864-4869. [CrossRef]

52. Kawasaki, M.; Alhajeri, S.N.; Xu, C.; Langdona, T.G. The development of hardness homogeneity in pure aluminum and aluminum alloy disks processed by high-pressure torsion. Mat. Sci. Eng. A Struct. 2011, 529, 345-351. [CrossRef]

53. Shirooyeh, M.; Xu, J.; Langdon, T.G. Microhardness evolution and mechanical characteristics of commercial purity titanium processed by high-pressure torsion. Mat. Sci. Eng. A Struct. 2014, 614, 223-231. [CrossRef]

54. Vollertsen, F.; Biermann, D.; Hansen, H.N.; Jawahir, I.S.; Kuzman, K. Size effects in manufacturing of metallic components. CIRP Ann. 2009, 58, 566-587. [CrossRef]

55. Fu, M.W.; Chan, W.L. A review on the state-of-the-art microforming technologies. Int. J. Adv. Manuf. Tech. 2013, 67, 2411-2437. [CrossRef]

(C) 2018 by the authors. Licensee MDPI, Basel, Switzerland. This article is an open access article distributed under the terms and conditions of the Creative Commons Attribution (CC BY) license (http:/ / creativecommons.org/licenses/by/4.0/). 